\title{
Revisiting Prostate Biopsy with 2014 ISUP Modified Gleason Score and Gleason Grade - A Cross Section Study
}

\author{
Manan B Shah ${ }^{1}$, Kalyani Raju²,*, Harish Kumar G ${ }^{3}$
}

${ }^{1}$ Resident, Department of Pathology, Sri Devaraj Urs Medical College, Kolar, Karnataka, India

${ }^{2}$ Professor and Head, Department of Pathology, Sri Devaraj Urs Medical College, Kolar, Karnataka, India

${ }^{3}$ Senior Resident, Department of Urology, Sri Devaraj Urs Medical College, Kolar, Karnataka, India

\section{Correspondence}

Kalyani Raju, Professor and Head, Department of Pathology, Sri Devaraj Urs Medical College, Kolar, Karnataka, India

Email: drkalyani@@rediffmail.com

\section{History}

- Received: Oct, 272018

- Accepted: Dec, 152018

- Published: Dec, 272018

DOI :

https://doi.org/10.15419/bmrat.v5i12.511

\section{Check for updates}

\section{Copyright}

( ) Biomedpress. This is an openaccess article distributed under the terms of the Creative Commons Attribution 4.0 International license.

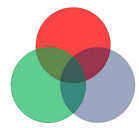
The Open Access Publisher

\begin{abstract}
Background: Prostatic carcinoma is one of the most common carcinomas among men throughout the world. Gleason score (GS) system is used in reporting and assessing the prognosis of prostatic carcinoma. The GS has undergone modifications. The objective of this study is to evaluate the impact of the new 2014 ISUP Modified Gleason System and Gleason grading (GG) on reporting of prostatic carcinoma. Methodology: This is a retrospective Study. All cases reported as adenocarcinoma prostate from January 2013 to July 2018 were included in the study. The GS done previously as per 2005 criteria was noted. The GS system and GG were done on the microslides retrieved as per 2015 criteria and compared with that of GS already recorded and also with old risk stratification. Results: Comparing the GS of 2005 and 2015 criteria, there was a marked decrease (80\%) in Gleason score 6; among these cases, 80\% cases were graded as score 7, and 20\% cases were graded as score 8 . There is also a $28.57 \%$ decrease in Gleason score 8 and $60 \%$ increase in Gleason score 9 due to the new criteria for pattern 4. The GG 1,2,3,4 and 5 constituted 3.03\%, $18.18 \%, 15.15 \%, 15.15 \%$, and $48.49 \%$ of cases respectively. Conclusion: The new GS and GG has more impact on prognosis of adenocarcinoma prostate as GS 6 has better prognosis and GG gives better risk stratification compared to the previous risk stratification.

Key words: Adenocarcinoma prostate, Gleason grade, Gleason score, Prostate
\end{abstract}

\section{INTRODUCTION}

Prostatic carcinoma is one of the most common carcinomas among men throughout the world and is the second most common cause of cancer death in men after lung carcinoma ${ }^{1-6}$.

Ever since the Gleason score (GS) system (Table 1) was introduced back in 1966, it has had a great impact on reporting and prognosis of prostatic carcinoma. The system also predicts local recurrence or distant metastasis in patients receiving no treatment, chemotherapy, radiation therapy, radical prostatectomy, and other forms of treatment.

The original Gleason score system was based only on the architectural pattern of tumors per se using a fivepoint scale system with pattern 1, 2 and 3 closely resembling a normal prostate gland while pattern 4 and 5 showing an increase in number and abnormality in glandular architectures ${ }^{8-10}$. A unique feature about this system was that instead of assigning the worst grade as the carcinoma grade, the Gleason grade was defined as the sum of two most common patterns of cancer and reported as Gleason score. After multiple research and studies by Gleason and Mellinger, they described Gleason pattern 4 as fused glands frequently with pale cells which may resemble hypernephroma of the kidney ${ }^{7,11}$.
A conference was convened in 2005 by The International society of urological pathology (ISUP) to achieve consensus in controversial areas in the Gleason system ${ }^{7}$. After discussion, 2005 ISUP Modified Gleason system was introduced (Table 2$)^{7,12}$. Differences between the original Gleason system and the 2005 ISUP modified Gleason system are listed in Table $3^{7}$.

The decision-making criteria for active surveillance were still not clear-cut with 2005 ISUP Modified Gleason system. Gleason score less than or equal to 6 on core needle biopsy (CNB) yielded a higher Gleason score than in the resected prostatectomy (RP) specimen. Another major pitfall of 2005 ISUP Modified Gleason system was that the GS 7 includes both $3+4$ and $4+3$. However, studies have shown a better clinical outcome for patients with $3+4$ versus $4+3$. Moreover Gleason score $3+3$ was considered as intermediate risk, even though the GS 6 is the lowest score used by pathologists in reporting prostate biopsy ${ }^{7,13}$.

The 2014 ISUP Gleason score and Gleason grade groups (GG) system were introduced to overcome the 2005 Gleason score pitfalls. The new system includes Gleason grade groups ranging from 1 to 5 (Table 4) ${ }^{14,15}$. This adjustment provides a higher consistency between RP specimen and core biopsy. It 


\begin{tabular}{|c|c|}
\hline Pattern & Description \\
\hline 1 & $\begin{array}{l}\text { Very well-differentiated, small, closely packed, uniform glands in essentially circumscribed } \\
\text { masses. }\end{array}$ \\
\hline 2 & $\begin{array}{l}\text { Similar to pattern } 1 \text { but with moderate variation in size and shape of glands and more atypia in } \\
\text { the individual cells; cribriform pattern may be present, still essentially circumscribed, but more } \\
\text { loosely arranged. }\end{array}$ \\
\hline 3 & $\begin{array}{l}\text { Similar to pattern } 2 \text { but marked irregularity in size and shape of glands, with tiny glands or } \\
\text { individual cells invading stroma away from circumscribed masses or solid cords and masses with } \\
\text { easily identifiable glandular differentiation within most of them. }\end{array}$ \\
\hline 4 & $\begin{array}{l}\text { Large clear cells growing in a diffuse pattern resembling hypernephroma; may show gland for- } \\
\text { mation. }\end{array}$ \\
\hline 5 & $\begin{array}{l}\text { Very poorly differentiated tumors; usually solid masses or diffuse growth with little or no differ- } \\
\text { entiation into glands. }\end{array}$ \\
\hline
\end{tabular}

\section{Table 2: 2005 ISUP Modified Gleason System ${ }^{7}$}

Pattern

1

2

3

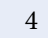

5

\section{Description}

Circumscribed nodule of closely packed but separate, uniform, rounded to oval, medium-sized acini (larger glands than pattern 3 ).

Like pattern 1, fairly circumscribed, yet at the edge of the tumor nodule, there may be minimal infiltration. Glands are more

loosely arranged and not quite as uniform as Gleason pattern 1.

Discrete glandular units. Typically smaller glands than seen in Gleason pattern 1 or 2. Infiltrates in and among non-neoplastic prostate acini.

Marked variation in size and shape. Smoothly circumscribed small cribriform nodules of the tumor.

$4 \quad$ Fused microacinar glands. Ill-defined glands with poorly formed glandular lumina. Large cribriform glands. Cribriform glands with

an irregular border. Hypernephromatoid.

Essentially no glandular differentiation, composed of solid sheets, cords or single cells. Comedocarcinoma with central necrosis surrounded by papillary, cribriform or solid masses. has redefined the pattern 4 and introduced new grade groups for better prediction of prognosis of prostate cancer ${ }^{13}$.

The objective of the study is to evaluate the impact of the new 2014 ISUP Modified Gleason System and Gleason grading in reporting prostatic carcinoma.

\section{METHODS}

This study is a Retrospective study. All cases reported as Adenocarcinoma prostate from January 2013 to July 2018 in the Pathology department in coordination with the Department of Urology at R.L. Jalappa Hospital and Research Centre attached to Sri Devraj Urs Medical College, Tamaka, Kolar were included in the study. The patient details were collected from case files of hospital record section.

All Prostatic Needle biopsy (NB), Transurethral resec- tion of the prostate (TUPR) and resected prostate (RP) specimens diagnosed as Adenocarcinoma of prostate were included in the study. All NB, TUPR and RP specimens diagnosed other than Adenocarcinoma of prostate and patients who had received chemotherapy, radiotherapy or any other mode of treatment before biopsy were excluded from the study. NB, TURP and RP specimen microslides which were previously reported using the 2005 Gleason score were retrieved from the Department of Pathology and reclassified by the consultant pathologist and resident of Pathology according to the 2014 International society of urological pathology (ISUP) consensus conference (Table 5) and the newer Gleason Grade (GG) group system criteria (Gleason grade 1 to 5) (Table 6) ${ }^{14-16}$. The findings were compared with the reports signed out previously using the 2005 Gleason score. 
Table 3: Comparison of 1966 Gleason scoring system with 2005 ISUP Modified Gleason System ${ }^{7}$

\section{Original Gleason system}

A diagnosis of GS $<4$ is possible on NB.

A partial cribriform pattern, large cribriform is diagnosed as Gleason pattern 3.

The same GS is used for NB and RP specimens.

High-grade tumor of small quantity $(<5 \%)$ on NB should be excluded based on GS (5\% threshold rule).

Tumors on NB should be graded by listing the primary and secondary patterns (i.e., excluding tertiary pattern).

The GS of RP specimens should be assigned based on the primary and secondary patterns.

Separate or overall scoring is used to assess all grades of NB specimens.

The grade of the largest portion should be assigned even if the second largest portion is of higher grade.

\section{ISUP Modified Gleason System}

GS of NB specimens $<4$ is rarely if ever made.

Most cribriform patterns would be diagnosed as Gleason pattern 4; specimens with only rare cribriform lesions would satisfy the diagnostic criteria for cribriform pattern 3 .

Different GS is used for NB and RP specimens.

High-grade tumor of any quantity on NB should be included within the GS.

For the tertiary pattern on NB specimens, both the primary pattern and

the highest grade should be recorded.

For RP specimens, the pathologist should assign the GS based on the primary and secondary patterns with a comment on the tertiary pattern.

When NB specimens show different grades in separate cores, individual

GS should be assigned to these cores (separate scoring).

When RP specimens show different grades in separate tumor nodules,

a separate GS should be assigned to each of the dominant tumor nodules.

\begin{tabular}{|c|c|c|}
\hline $\begin{array}{l}\text { Gleason Grade } \\
\text { group }\end{array}$ & Score & Definition \\
\hline 1 & $3+3=6$ & Only individual discrete well-formed glands \\
\hline 2 & $3+4=7$ & $\begin{array}{l}\text { Predominantly well-formed glands with a lesser component of } \\
\text { poorly/fused/cribriform glands }\end{array}$ \\
\hline 3 & $4+3=7$ & $\begin{array}{l}\text { Predominantly poorly formed/fused/cribriform glands with a lesser } \\
\text { component of well-formed glands }\end{array}$ \\
\hline 4 & $\begin{array}{c}5+3,3+5,4+4 \\
(\text { Gleason score } 8)\end{array}$ & $\begin{array}{l}\text { Only poorly formed/fused/cribriform glands }(>95 \%) \text { or Predominantly } \\
\text { well-formed glands and lesser component lacking glands or Predomi- } \\
\text { nantly lacking glands and a lesser component of well-formed glands }\end{array}$ \\
\hline 5 & $\begin{array}{l}\text { Gleason scores } 9 \text { and } \\
10\end{array}$ & $\begin{array}{l}\text { Lack of gland formation (or with necrosis) }(>95 \%) \text { with or without } \\
\text { formed/fused } \\
\text { /cribriform glands }\end{array}$ \\
\hline
\end{tabular}

\section{Statistical analysis}

All the collected data were grouped and entered into Microsoft Excel. All the continuous variables were presented as mean and standard deviation. Chisquare test was the test of significance for categorical data. SPSS 22 software was used for analysis. $\mathrm{P}<0.05$ was considered statistically significant.

\section{RESULTS}

Age distribution of patients ranges from 40 to 82 years with the mean age of 70 years. A total of 33 cases were studied. As per the Gleason score according to newer guidelines from the 2014 International society of urological pathology (ISUP) consensus conference and the newer Gleason Grade (GG) group system criteria (Gleason grade 1 to 5 ), the Gleason grade 1,2,3,4 and 5 constituted $3.03 \%, 18.18 \%, 15.15 \%, 15.15 \%$ and $48.49 \%$ of cases respectively (Tables 5 and 6). 
Table 5: Number of cases with Gleason score according to the ISUP 2005 and reclassificationaccording to 2014 ISUP Gleason score system guidelines

\begin{tabular}{ccc}
\hline Gleason Score & ISUP 2005 MGSS & ISUP 2014 MGSS \\
\hline 2 & 1 & - \\
3 & & - \\
4 & 1 & - \\
6 & 5 & 1 \\
6 & 9 & 11 \\
7 & 7 & 5 \\
8 & 9 & 15 \\
9 & 1 & 1 \\
\hline
\end{tabular}

Table 6: Gleason Grade (GG) group system in the present study

\begin{tabular}{ccc}
\hline Gleason Grade & Number of cases & $\%$ of cases \\
\hline 1 & 1 & $3.03 \%$ \\
2 & 6 & $18.18 \%$ \\
3 & 5 & $15.15 \%$ \\
4 & 5 & $15.15 \%$ \\
5 & 16 & $48.49 \%$ \\
\hline
\end{tabular}

All the cases were also classified into three different categories according to older Clinical risk stratification (Table 7) and compared with the newer Gleason grade groups ( Table 8) ${ }^{13}$. Low-risk, Intermediaterisk, and high-risk category constituted $21.21 \%$, $27.27 \%$ and $51.52 \%$ of cases respectively.

\section{DISCUSSION}

Prostatic carcinoma is one of the most common carcinomas among men throughout the world and ranks second among cancer deaths in males after lung carcinoma ${ }^{1-6}$. The incidence and prevalence of prostate carcinoma vary in different regions of the world, with the lowest in South Asia and the highest in North America ${ }^{6}$.

It is observed that one out of six men is having probably of getting diagnosed with Prostatic carcinoma in his lifetime. It has various clinical behaviors, from insignificant cancers which are discovered incidentally to very aggressive cancers. The diagnosis of the prostatic carcinoma is based on the invasion of the basement membrane of an individual gland by cancerous cells, and the grading is done according to the architectural pattern of the glands ${ }^{17}$.
In 1966 Gleason had created a unique system of grading the prostatic carcinoma based solely on the architectural pattern. They used a five-point scoring system (Table 1). According to this scoring system grade 1,2 and 3 represented the pattern which closely resembles the normal architecture of a healthy prostatic gland. Pattern 4 and 5 represented an increasingly abnormal architecture of the glands ${ }^{7}$. After multiple revisions, Gleason and Mellinger in association with Veterans Administration Cooperative Urological Research Group presented a new scoring system which is now known as the Original Gleason grading system. The unique feature about this system was that rather assigning the worst or highest grade to carcinoma in one specimen, the grading was defined as the total of two most commonly occurring patterns and finally reported as Gleason score ${ }^{7}$.

The original Gleason score system had some controversial areas such as overgeneralization of the grading system, confusion in definition of patterns, confusion in reporting of the secondary grade whether it is lower or higher grade present in limited extent, concept, and controversies in reporting, importance of tertiary Gleason pattern, advantages, and importance 
Table 7: Old clinical risk stratification in the present

study

\begin{tabular}{ccc}
\hline Risk & Number of the cases & $\%$ of cases \\
\hline Low risk & 7 & $21.21 \%$ \\
Intermediate risk & 9 & $27.27 \%$ \\
High risk & 17 & $51.52 \%$ \\
\hline
\end{tabular}

Table 8: Comparison between old clinical risk stratification and GG group system in the present study

\begin{tabular}{lcccccc}
\hline Risk & GG 1 & GG 2 & GG 3 & GG 4 & GG 5 & Total \\
\hline Low risk & 1 & 4 & 1 & 1 & - & 7 \\
$\begin{array}{l}\text { Intermediate } \\
\text { risk }\end{array}$ & - & 1 & 4 & 3 & 1 & 9 \\
High risk & - & 1 & - & 1 & 15 & 17 \\
Total & 1 & 6 & 5 & 5 & 16 & 33 \\
\hline
\end{tabular}

Table 9: Comparisionof findings of the present study with Paolo Dell'oglio et al. ${ }^{18}$

\begin{tabular}{lll}
\hline & Paolo et al. $2016^{18}$ & Present study 2018 \\
\hline \% of cases in intermediate group & $33.33 \%(3311 / 9728)$ & $27.27 \%(9 / 33)$ \\
GG group 2 & $7.177 \%(2323 / 3311)$ & $55.55 \%(5 / 9)$ \\
GG group 3 & $28.23 \%(918 / 3311)$ & $44.44 \%(4 / 9)$ \\
\hline
\end{tabular}

of percent pattern 4 and 5 . In addition, reporting of needle biopsy with different grades of tumor in different cores. The ISUP convened a conference in San Antonio in 2005 to address these issues. This conference led into the newer "2005 ISUP Modified Gleason System" (Table 2). The 2014 ISUP Gleason score and Gleason grade groups (GG) system was introduced to overcome 2005 Gleason score pitfalls. It has redefined the pattern 3 and 4 and introduced new GG groups (Table 4$)^{7,14,15}$ for better prediction of prognosis of prostate cancer ${ }^{13}$.

According to the 2014 ISUP conference, Gleason pattern 3 (Figure 1) is defined as well-formed glands of varying size which also includes branching glands. Pattern 3 glands should form discrete units, such that one can draw a full circle around individual glands. Small glands now also accepted as pattern 3 if they are well formed and not fused. Pattern 3 glands are readily recognizable at scanner $40 \mathrm{x}$ magnification). Pattern 4 (Figure 2) glands are defined as poorly formed, fused or cribriform glands. In the original grading system, the regular and rounded cribriform patterns were included in pattern 3 , but now they are recognized as pattern 4 . Scores 2 to 5 are no longer assigned in the new Gleason grade group system ${ }^{13}$.
In the present study, we have revisited 33 prostatic carcinoma microslides and recategorized according to the new definition and criteria laid by 2014 ISUP conference (Tables 5 and 6). The new definition of pattern 3 and pattern 4 had a major impact on histopathology reporting of prostatic adenocarcinoma. We observed that most of prostatic adenocarcinomas with the cribriform pattern were reported as score 3 due to lack of precise definition. Most of these cribriform patterns were non-complex. Due to the strict criteria for pattern 3 laid by 2014 ISUP conference, there was an overall decrease in reporting of score 6 and the same are now graded as score 7 or 8 because of the inclusion of all types of the cribriform pattern (Complex or non-complex) in the pattern 4 . In this study, there was a marked decrease (80\%) in reporting of Gleason score 6 . Among these reclassified cases, $80 \%$ of the cases were graded as score 7 , and $20 \%$ of the cases were graded as score 8 . There is also a $28.57 \%$ decrease in reporting of Gleason score 8 and $60 \%$ increase in reporting of Gleason score 9 due to the new criteria of the pattern 4 .

According to Jennifer $G$ et al., the consequence of considering all cribriform pattern and poorly formed glands as pattern 4 which was considered pattern 3 previously is that the new score 6 will have fewer cases 


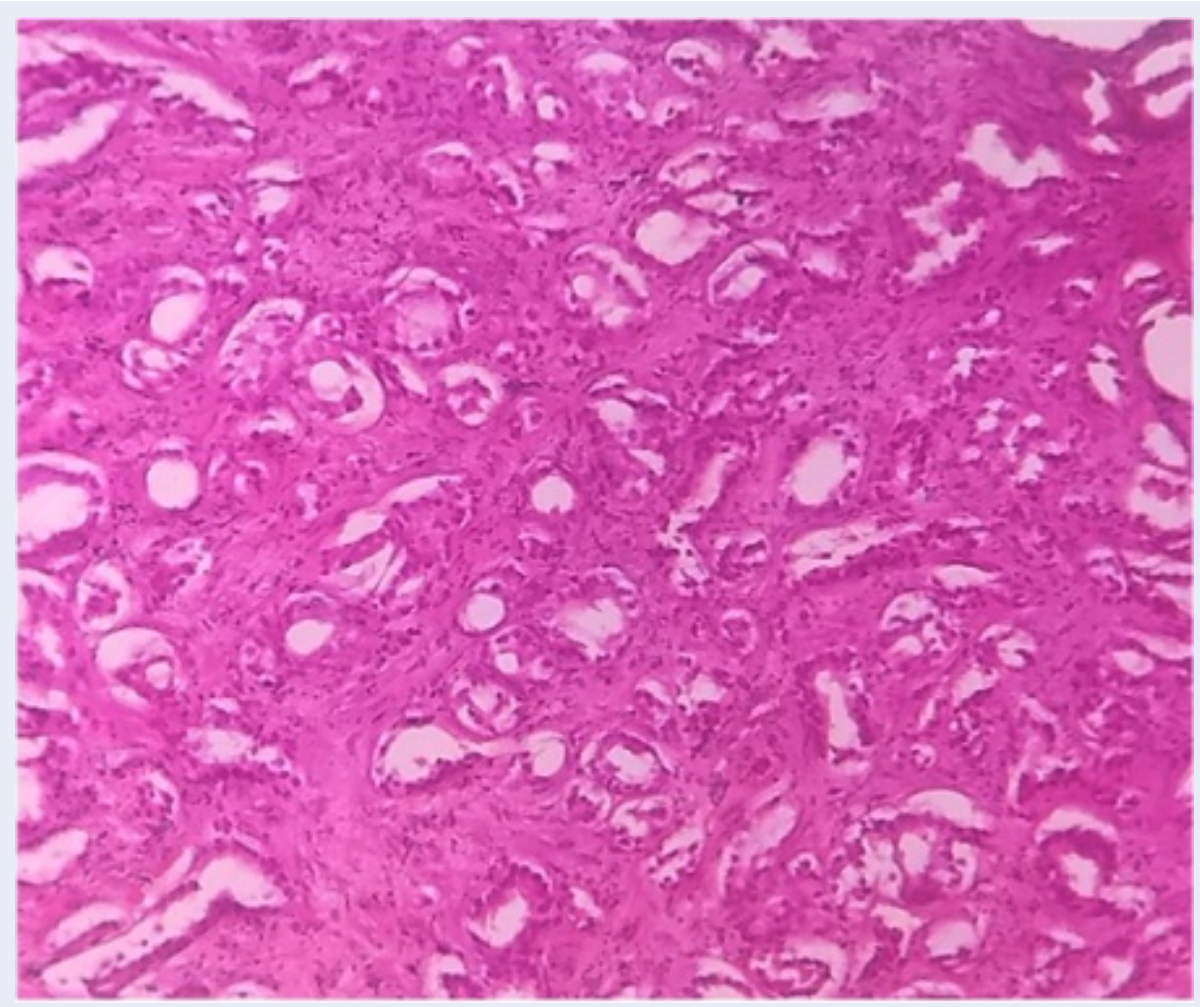

Figure 1: Microphotograph shows pattern 3 well formed glands (H\&E, X100).

and better prognosis compared to the old score 6 , and there is also an increase in the number of score $7 \mathrm{tu}$ mors $^{13}$.

In the old clinical risk stratification (Table 7) the intermediate group consisted of all tumors with score 7 including both score $3+4$ and score $4+3$. Accordingly, in this study, $27.27 \%$ of tumors were categorized as the intermediate risk group. Several studies have suggested that score $4+3$ shows poorer prognosis compared to score $3+4$ and that is why in 2014 modified Gleason grade (GG) group system both $3+4$ tumors and $4+3$ tumors were classified in different groups as GG group 2 and 3 respectively ${ }^{13,16,17}$. In this study, we experienced that the new definition of pattern 3 and pattern 4 with the inclusion of new Gleason grade groups had a major impact on intermediate risk groups which is now divided into GG2 and GG3 according to the predominant pattern. Accordingly, when the intermediate group was reclassified as per the GG group system, GG 2, 3, 4 and 5 constituted $11.11 \%, 44.45 \%, 33.33 \%$, and $11.11 \%$ of cases respectively (Table 8).

A study done by Paolo Delloglio et al. reported that $33.33 \%$ cases (3311/9728 cases) were in the intermediate group and when these cases were reclassified according to the GG group system, GG 2 and GG 3 had
$71.77 \%$ and $28.23 \%$ of the cases respectively ${ }^{18}$. This states that the old clinical risk stratification is very vague and misleading. These findings are compared to the findings of the present study in Table 9.

A study done in 2016 by Jennifer G et al. stated that the five-year biochemical risk-free survival for the new GG groups based on radical prostatectomy were $96 \%, 88 \%, 63 \%, 48 \%$, and $26 \%$ respectively. This finding suggested that the new GG group system is more uniform and accurate in which grade 1 (least grade) have the best prognosis or least recurrence, and grade 5 (highest grade) have the worst prognosis or highest recurrence ${ }^{13}$.

2014 ISUP conference has redefined the patterns 3 and 4 by which the difference between these two patterns is now more precise and clear. The new Gleason grading system is more precise and accurate in predicting the prognosis of prostatic carcinoma. However, this system still has certain limitations and pitfalls, which require further revision.

The limitations of this study are those only prostatic biopsy and TURP chips were considered for the study, there were no RP specimens in the study which may not completely reflect the actual tumor grade. In addition, the numbers of cases are small. Larger sample 


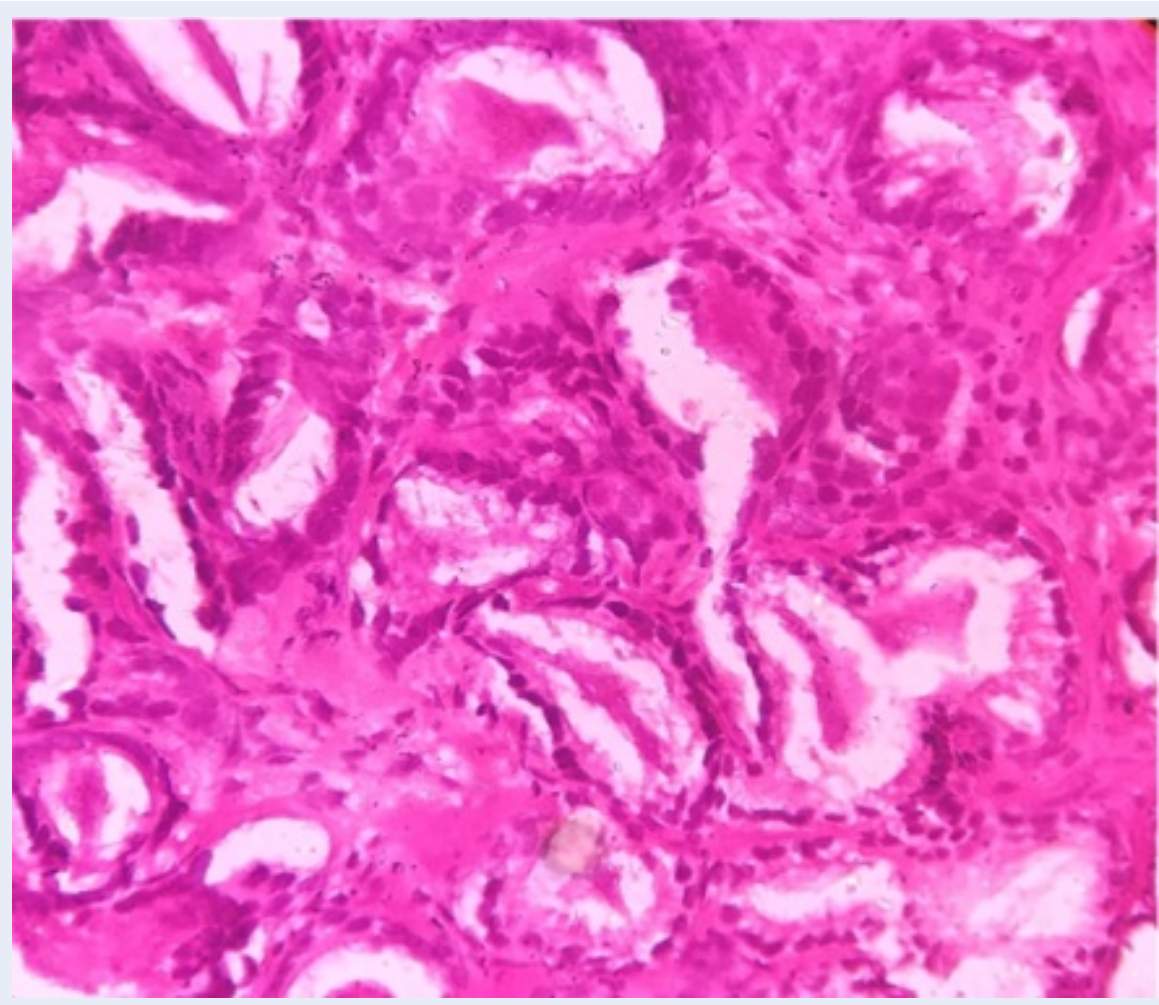

Figure 2: Microphotograph shows pattern 4 irregularly formed glands (H\&E, X400).

size is required for a more definite conclusion. However, the present study showed the advantage of using the new 2014 ISUP GG group system which accurately predicts the prognosis of patients.

\section{CONCLUSIONS}

While the old clinical risk stratification was not well defined, the new 2014 ISUP GG group system is prognostically more useful which can reassure that grade group 1 has better survival and they can be followed with active surveillance. Moreover, according to the old risk stratification groups, two diverse groups of patient (Pattern 3+4 and pattern $4+3$ ) were categorized in the intermediate risk stratification group. However, it has been reported that the patients with pattern $3+4$ have a better prognosis than the patients with pattern $4+3$, which is the reason why they should be reclassified into GG2 and GG3 respectively. This reclassification is more effective in deciding the prognosis of the patients.

\section{ABBREVIATIONS \\ CNB: Core needle biopsy \\ GG: Gleason Grade \\ GS: Gleason Score}

ISUP: International society of urological pathology ISUP

NB: Needle biopsy

RP: Resected prostate

TURP: Transurethral resection of the prostate

\section{COMPETING INTERESTS}

The authors report no conflicts of interest in this work.

\section{AUTHORS' CONTRIBUTIONS}

Manan B Shah: Data collection, drafting the research proposal, editing.

Kalyani Raju: Concept, drafting the research proposal, editing \& final checking.

Harish Kumar G: Surgeon, editing.

\section{REFERENCES}

1. Center MM, Jemal A, Lortet-Tieulent J, Ward E, Ferlay J, Brawley $O$. International variation in prostate cancer incidence and mortality rates. European Urology. 2012;61(6):1079-92. Available from: DOI:10.1016/j.eururo.2012.02.054.

2. Bashir MN. Epidemiology of prostate cancer. Asian Pacific Journal of Cancer Prevention. 2015;16:5137-41. Available from: Doi:10.7314/apjcp.2015.16.13.5137.

3. Pakzad R, Mohammadian-Hafshejani A, Ghoncheh M, Pakzad I, Salehiniya $\mathrm{H}$. The incidence and mortality of prostate cancer and its relationship with development in Asia. Prostate International. 2015;3(4):135-40. Available from: DOI:10.1016/j. prnil.2015.09.001. 
4. Pakzad R, Rafiemanesh H, Ghoncheh M, Sarmad A, Salehiniya $\mathrm{H}$, Hosseini $\mathrm{S}$. Prostate cancer in Iran: trends in incidence and morphological and epidemiological characteristics. Asian Pacific Journal of Cancer Prevention. 2016;17(2):839-43. Available from: Doi:10.7314/apjcp.2016.17.2.839.

5. Schröder FH, Hugosson J, Roobol MJ, Tammela TL, Ciatto S Nelen V, et al. Prostate-cancer mortality at 11 years of followup. New England Journal of Medicine. 2012;366(11):981-990. Available from: 10.1056/NEJMoa1113135.

6. Torre LA, Bray F, Siegel RL, Ferlay J, Lortet-Tieulent J, Jemal A. Global cancer statistics, 2012. CA: a Cancer Journal for Clinicians. 2015;65:87-108. Available from: DOI:10.3322/caac. 21262.

7. Montironi R, Cheng L, Lopez-Beltran A, Scarpelli M, Mazzucchelli R, Mikuz G. Original Gleason system versus 2005 ISUP modified Gleason system: the importance of indicating which system is used in the patientś pathology and clinical reports. European Urology. 2010;58:369-73. Available from: DOI:10. 1016/j.eururo.2010.04.028.

8. Bailar JC, Mellinger GT, Gleason DF. Survival rates of patients with prostatic cancer, tumor stage, and differentiationpreliminary report. Cancer Chemotherapy Reports Part 1. 1966;50:129-36.

9. Gleason DF. Classification of prostatic carcinomas. Cancer Chemotherapy Reports Part 1. 1966;50:125-8.

10. Mellinger GT, Gleason D, Bailar J. The histology and prognosis of prostatic cancer. The Journal of Urology. 1967;97:331-7. Available from: Doi:10.1016/s0022-5347(17)63039-8.

11. Gleason DF, Mellinger GT, Arduino LJ, Bailar JC, Becker LE, Berman HI. Prediction of prognosis for prostatic adenocarcinoma by combined histological grading and clinical staging. The Journal of Urology. 1974;111:58-64. Available from: Doi:10.1016/s0022-5347(17)59889-4.

12. Epstein Jl, Allsbrook WC, Amin MB, Egevad LL. The 2005
International Society of Urological Pathology (ISUP) consensus conference on Gleason grading of prostatic carcinoma. The American Journal of Surgical Pathology. 2005;29:122842. Available from: DOI:10.1097/01.pas.0000173646.99337.b1.

13. Gordetsky J, Epstein J. Grading of prostatic adenocarcinoma: current state and prognostic implications. Diagnostic Pathology. 2016;11:25. Available from: DOI:10.1186/s13000-0160478-2.

14. Erickson A, Sandeman K, Lahdensuo K, Nordling S, Kallajoki $M$, Seikkula $H$. New prostate cancer grade grouping system predicts survival after radical prostatectomy. Human Pathology. 2018;75:159-66. Available from: DOI:10.1016/j.humpath 2018.01.027.

15. Epstein Jl. Prostate cancer grading: a decade after the 2005 modified system. Modern Pathology. 2018:31:S47-63. Available from: DOI:10.1038/modpathol.2017.133.

16. Epstein Jl, Amin MB, Reuter VE, Humphrey PA. Contemporary Gleason grading of prostatic carcinoma. An update with discussion on practical issues to implement the 2014 international society of urological pathology (ISUP) consensus conference on Gleason Grading of prostatic carcinoma. The American Journal of Surgical Pathology. 2017;41:e1-7. Available from: Doi:10.1097/pas.0000000000000820.

17. Jonathan IE, Lotan TL. The lower urinary tract and male genital system. In: Kumar V, Abbas AK, Aster JC, editors. Robbins and Cotran Pathologic Basis of Disease. vol. 21. Saunders: Philadelphia; 2015. p. 959-990.

18. Dell'Oglio P, Karnes RJ, Gandaglia G, Fossati N, Stabile A, Moschini $M$, et al. The New Prostate Cancer Grading System Does Not Improve Prediction of Clinical Recurrence After Radical Prostatectomy: Results of a Large, Two-Center Validation Study. The Prostate. 2017;77(3):263-273. Available from: $10.1002 /$ pros. 23265 